\title{
Management of Ingested Foreign Bodies in Childhood
}

\author{
LEWIS SPITZ
}

British Medical fournal, 1971, 4, 469-472

\section{Summary}

A total of 660 patients with ingested foreign bodies admitted to the general surgical services in two children's hospitals in Liverpool are reviewed. Endoscopic removal (205 cases) is recommended for all foreign objects impacted in the oesophagus, with the exception of rounded or blunt objects in the lower third, which should be observed for a maximum of 12 hours. The indications for laparotomy for removal of a foreign body (43 cases, $6.5 \%$ ) are the danger of perforation and failure of progression. The ingestion of a long slender object-for example a hair-grip-in a child under 2 years of age, is an absolute indication for prophylactic operative removal owing to the high incidence of impaction and perforation of the duodenum.

\section{Introduction}

The majority of ingested foreign bodies causing trouble do so in the oesophagus $(20-30 \%)$. Impaction commonly occurs at sites of anatomical constrictions-in the post-cricoid region and at the levels of the aortic arch; the left main bronchus, and the diaphragm. Once the foreign object has safely entered the stomach uneventful passage through the intestinal tract can be expected in $80-90 \%$ of cases. The levels at which progress is impeded are the pylorus, the duodenum, the duodenojejunal flexure, the ileocaecal region, and at sites of developmental anomalies-for example, stenoses. ${ }^{1-4}$

\footnotetext{
Alder Hey Children's Hospital, Liverpool 12

LEWIS SPITZ, F.R.C.S.ED., (Smith and Nephew Fellow). At present, Surgical Registrar, Department of Surgery, University of Witwatersrand, Medical School, Johannesburg, South Africa
}

This paper attempts to identify those patients in whom surgical intervention (endoscopic or operative) is indicated and to formulate a general plan of management.

\section{Material and Methods}

In the period $1950-69,660$ patients under the age of 16 years (Fig. 1) were admitted to the surgical services of the Alder Hey Children's Hospital and the Royal Children's Hospital, Liverpool. Many more patients, not considered here, treated only in

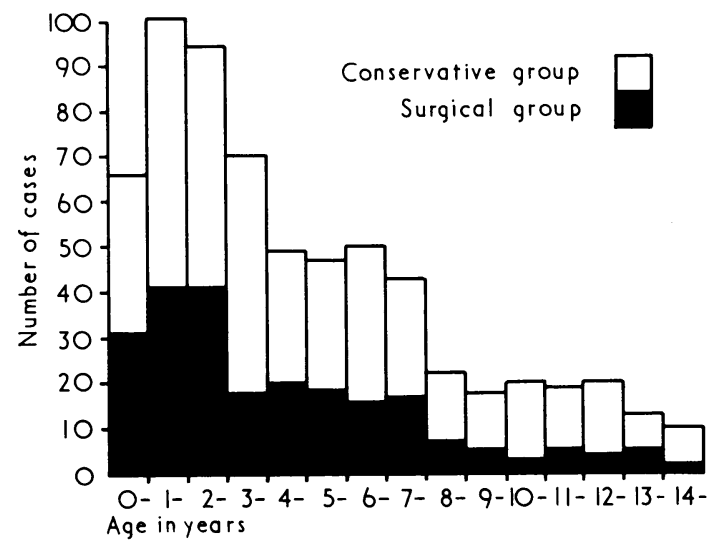

FIG. 1-Age distribution of patients and type of treatment given.

the casualty and outpatient departments, had ingested foreign bodies of which uneventful passage was anticipated. Of the 660 cases 62 had a history strongly suggestive of an ingested foreign body but neither endoscopic nor radiological studies confirmed this. Four groups of foreign objects were recognized (Table I). The foodstuff considered caused obstruction by virtue of inefficient peristalsis and motility of the viscus concerned. 
TABLE I-Nature of Foreign Body and Type of Treatment used

\begin{tabular}{|c|c|c|c|c|}
\hline & \multirow{2}{*}{$\begin{array}{l}\text { No. of } \\
\text { Cases }\end{array}$} & \multirow{2}{*}{ Conservative } & \multicolumn{2}{|c|}{ Surgical } \\
\hline & & & Endoscopic & Operative \\
\hline 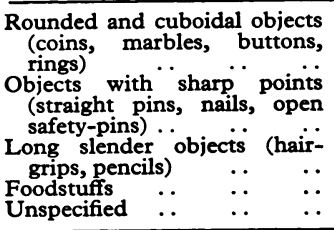 & $\begin{array}{r}307 \\
235 \\
90 \\
8 \\
20\end{array}$ & $\begin{array}{r}145 \\
193 \\
55 \\
17\end{array}$ & 157 & $\begin{array}{r}5 \\
5 \\
35\end{array}$ \\
\hline $\begin{array}{llll}\text { Total } & \ldots & \ldots & \ldots\end{array}$ & 660 & 410 & 205 & 45 \\
\hline
\end{tabular}

Altogether 410 cases (62\%) were observed until either they were symptom-free or natural passage of the foreign body had occurred. Serial radiography was performed until the foreign body had safely passed the duodenojejunal flexure. The remaining 250 cases $(38 \%$ ) were treated surgically. For practical purposes three areas in the alimentary tract are considered here. (Table II).

TABLE II-Situation of Foreign Body and Type of Treatment used

\begin{tabular}{|c|c|c|c|c|c|}
\hline & & & $\begin{array}{l}\text { Total No. } \\
\text { of Cases }\end{array}$ & Conservative & Surgical \\
\hline 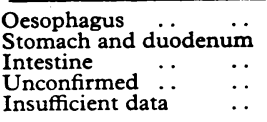 & $\begin{array}{l}\cdots \\
\cdots \\
\cdots \\
\cdots\end{array}$ & $\begin{array}{l}\because \\
\because \\
\cdots \\
\cdots\end{array}$ & $\begin{array}{r}231 \\
227 \\
30 \\
62 \\
110\end{array}$ & $\begin{array}{r}24 \\
184 \\
30 \\
62 \\
110\end{array}$ & $\begin{array}{r}207 \\
43\end{array}$ \\
\hline Total & $\ldots$ & . & 660 & 410 & 250 \\
\hline
\end{tabular}

\section{Oesophagus}

In a total of 231 patients the foreign object impacted in the oesophagus- $66 \%$ in the upper third, $20 \%$ in the midoesophagus, and $14 \%$ in the lower third (Fig. 2). Endoscopy was performed on 205 patients, with successful extraction of the

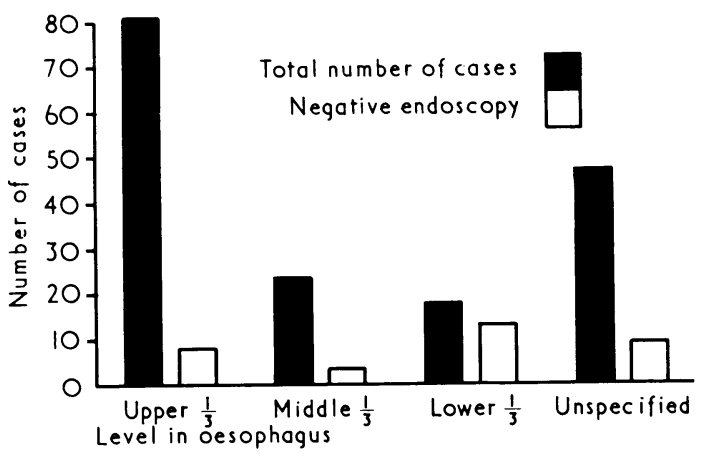

FIG. 2-Level in the oesophagus of the foreign body in relation to negative endoscopy.

foreign object in $81 \%$. The high incidence $(72 \%)$ of failure to find the foreign body, initially located in the lower oesophagus, owing to spontaneous progression into the stomach before or during endoscopy should be noted.

In two patients operative intervention was necessary to remove the foreign body after an unsuccessful attempt at endoscopy.

Case 1.-A boy age 1 year 11 months swallowed a key one month before admission. At oesophagoscopy the key, impacted at the level of the thoracic inlet (Fig. 3), could be neither extracted nor advanced into the stomach. After displacing it into the upper oesophagus the key was removed via a cervical oesophagotomy.

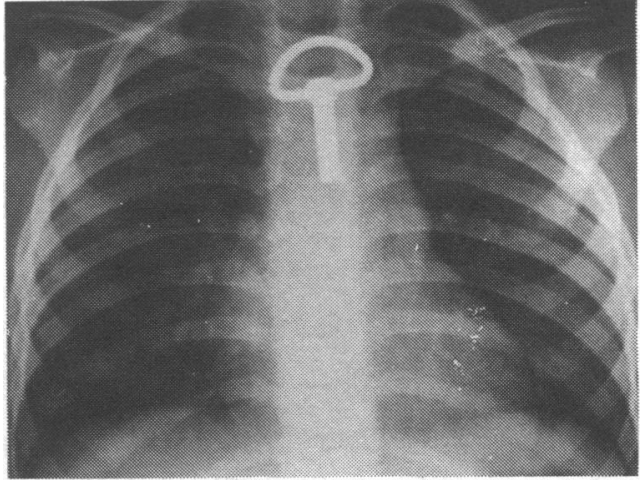

FIG. 3-Case 1. $X$-ray picture of chest showing key impacted at the level of the thoracic inlet.

Case 2.-A boy age 1 year 10 months suffered from "asthmalike" attacks for four months. Routine chest radiography showed the presence of a coin (Fig. 4). Endoscopic examination failed to visualize the coin, which on thoracotomy was found to have eroded through the oesophageal wall distal to the arch of the aorta.

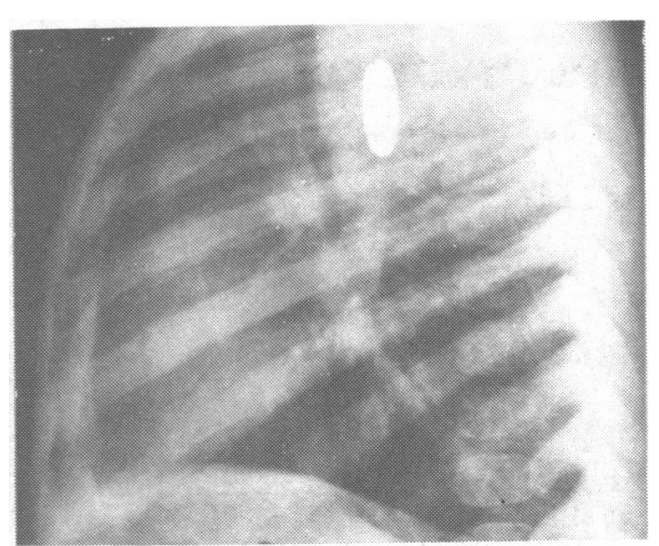

FIG. 4-Case 2. Lateral $x$-ray film of chest showing coin impacted at junction between middle and upper thirds of oesophagus.

\section{OESOPHAGEAL ATRESIA}

There is a group of patients who after successful repair of oesophageal atresia experience difficulty in swallowing solid, lumpy food ${ }^{5}$ owing to abnormal motility and peristalsis of the oesophagus either proximal (rarer) or distal (commoner) to the anastomotic site. In this series eight cases of this variety were encountered with a wide spectrum of foodstuffs and foreign material impacted in the oesophagus proximal to an adequate anastomosis. Endoscopic removal was successfully achieved in all cases, in one on eight separate occasions over a period of nine years.

\section{Stomach and Duodenum}

Operative intervention for removal of the foreign object was performed on $18.9 \%$ of patients in whom it had entered the stomach (43 out of a total of 227). The remaining 184 cases were successfully managed conservatively. There are two indications for operative intervention (Table III).

Danger of Perforation. - This may result from the ingestion of long slender objects with sharp ends-for example, hair-grips and open safety-pins-especially in children under the age of 2 years. The only case of actual perforation was that of a long embroidery needle penetrating the greater curvature of the stomach of a 13-year-od girl. 
TABLE III-Foreign Bodies removed at Laparotomy

\begin{tabular}{|c|c|c|c|c|}
\hline \multirow{2}{*}{$\begin{array}{l}\text { Nature of } \\
\text { Foreign Body }\end{array}$} & \multicolumn{2}{|c|}{ Situation } & \multicolumn{2}{|c|}{ Indication } \\
\hline & Stomach & Duodenum & $\begin{array}{l}\text { Danger of } \\
\text { Perforation }\end{array}$ & $\begin{array}{c}\text { Failure of } \\
\text { Progression }\end{array}$ \\
\hline $\begin{array}{ll}\text { Hair-grips } & \ldots \\
\text { Needles } \ldots & \ldots \\
\text { Open safety-pins.. } \\
\text { Coins } \ldots \\
\text { Trichobezoar } & \ldots \\
\text { Golliwog } . . & \ldots\end{array}$ & $\begin{array}{r}13 \\
1 \\
1 \\
4 \\
1\end{array}$ & $\begin{array}{r}18 \\
2 \\
2 \\
0 \\
1\end{array}$ & $\begin{array}{r}11 \\
3 \\
2\end{array}$ & $\begin{array}{r}20 \\
1 \\
4 \\
1 \\
1\end{array}$ \\
\hline
\end{tabular}

Failure of Progression.-A minimum period of 10-12 days' observation before surgery is recommended. It is of paramount importance that an $x$-ray film be taken immediately before operation.

Case 3.-A 5-year-old boy swallowed a $7 \mathrm{~cm}$ section of lead pencil radiologically demonstrated in the stomach 10 days before admission. In view of prolonged hold-up surgical intervention was recommended. A preoperative $x$-ray picture showed the pencil to have advanced into the duodenum (Fig. 5), where it remained

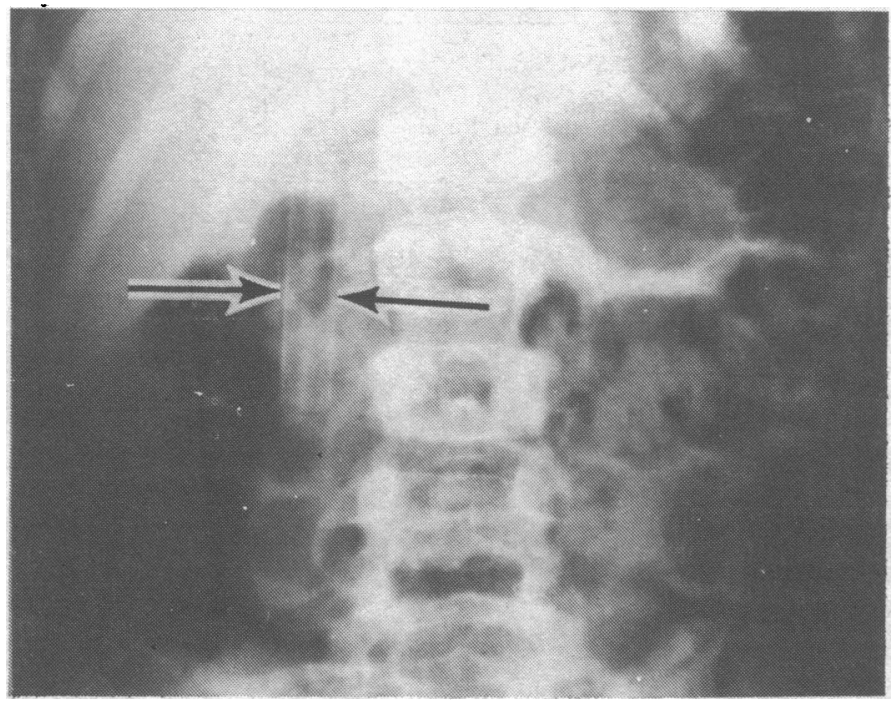

FIG. 5-Case 3. Abdominal $x$-ray picture showing lead pencil in right upper quadrant opposite second and third lumbar vertebrae.

impacted for the next three days. Surgery was again recommended but the pencil passed per rectum on the morning of the planned procedure.

A congenital anomaly, stenosis, or annular pancreas may be responsible for failure of progression.

Case 4.-A boy aged 3 years started vomiting after swallowing a small metal golliwog. Radiological investigation, including a barium meal, showed gross dilatation of the stomach and first and second parts of the duodenum (Fig. 6). He had experienced repeated episodes of copious vomiting during the first six months of life. At laparotomy the head of the golliwog was found to have impacted in the central aperture of a congenital duodenal web. After removal of the foreign object a duodeno-duodenostomy was performed.

Children who swallowed hair-grips (Kirby grips) constituted a unique group owing to the high incidence of operative removal $(39 \%)$. In 11 children less than 2 years old in whom the hairgrip was shown radiologically to be in the stomach emergency laparotomy was performed to remove it before impaction and perforation of the duedonum could occur. An essential initial step in the procedure is to prevent the foreign body from slipping into the duodenum by placing an occluding clamp across the pylorus.

In the remaining 20 cases operative removal was performed owing to failure of progression for an average of $10 \cdot 1$ days.

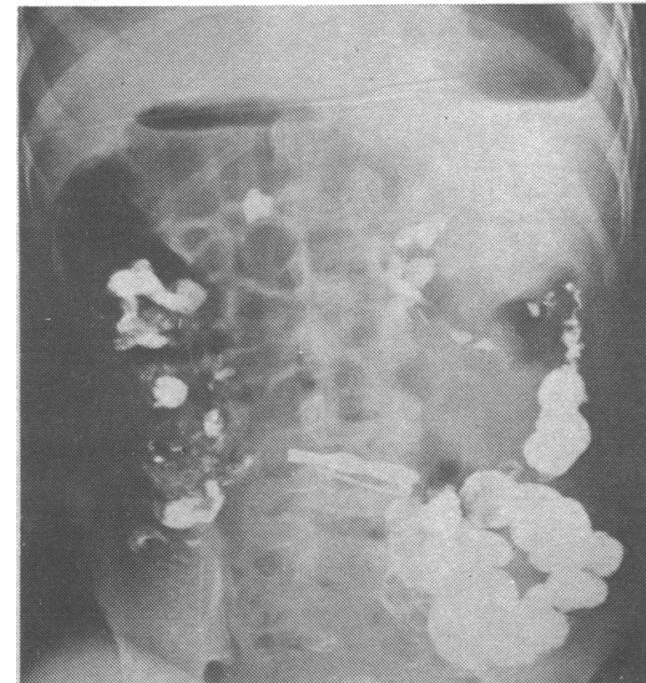

FIG. 6-Case 4. Erect abdominal $x$-ray picture showing clip of golliwog overlying fifth lumbar vertebrae, airfluid levels in stomach and first part of duodenum, and residual barium in the colon.

\section{TRICHOBEZOAR}

In Great Britain these are rare. The only case occurred in an 18-month-old child (Case 5) undergoing investigation for loss of weight, abdominal pain, hypochromic anaemia, and a palpable mass in the epigastrium. Radiological examination showed trichobezoar in the stomach (Fig. 7). At laparotomy a large hairball with tail extending into the jejunum was removed.

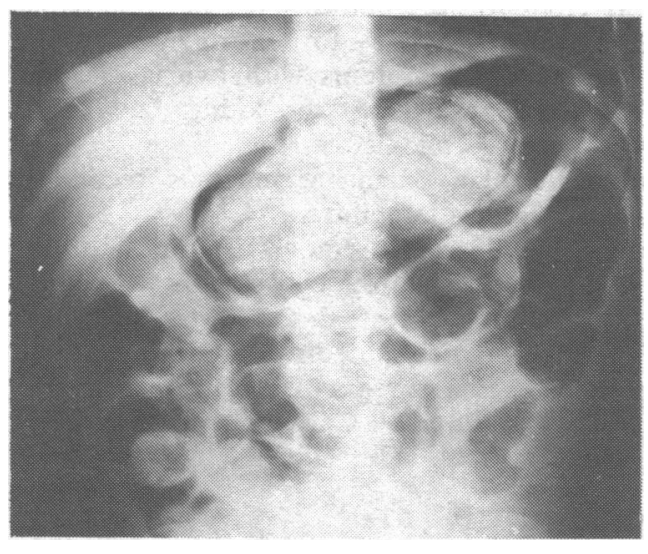

FIG. 7 -Case 5. Abdominal $x$-ray picture showing trichobezoar in the stomach.

\section{Intestinal Foreign Bodies}

Delay in progress may occur in the distal $10-20 \mathrm{~cm}$ of ileum, at the ileocaecal valve, at the anus, or at areas of congenital anomalies-for example, stenosis, Meckel's diverticulum, etc. Complications arising from prolonged impaction include intestinal obstruction, penetration with local or rarely generalized peritonitis, and intestinal fistulae. All the cases encountered in this series were successfully managed conservatively.

Case 6.-A girl aged 2 years 3 months was admitted to hospital for investigation of recurrent abdominal pain and vomiting. Physical examination showed nothing abnormal. $X$-ray film of the abdomen (Fig. 8) showed multiple radio-opaque foreign bodies in the colon. Complete evacuation resulted from the administration of an enema. 


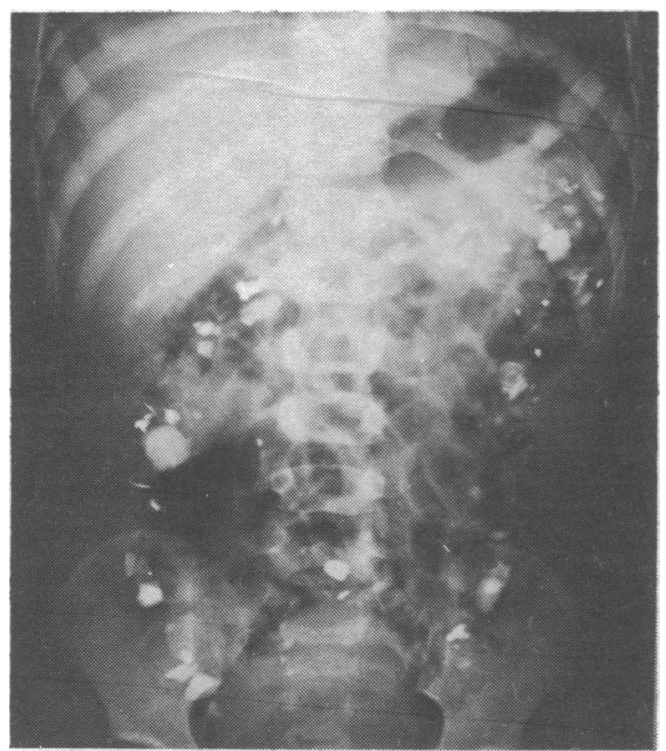

FIG. 8-Case 6. Abdominal $x$-ray picture showing multiple radio-opaque foreign bodies in the colon.

\section{Discussion}

The average time required for passage of foreign objects by the natural route is $5 \cdot 1$ days. No correlation exists between the age of the child and the time required for passage, but the nature of the object has been shown to be of some importance in this respect ${ }^{6}$-non-sharp objects 4.8 days, pointed at one end 5.8 days, pointed at both ends 7.0 days.

Impaction occurs most frequently in the upper oesophagus and in the duodenum, the latter also being the site where most perforations occur. In cases quoted in the literature duodenal perforations from foreign bodies have been responsible for a bizarre group of symptoms-for example, pain in the hip," septicaemia, ${ }^{8}$ urinary symptoms with pyuria and albuminuria secondary to perforation into the kidney, 10 and diarrhoea secondary to duodenocolic fistula. ${ }^{11}$

The following plan of management is recommended for ingested foreign bodies in children.

Oesophagus.-Endoscopic removal is indicated early for all foreign objects impacted in the oesophagus, with the exception of rounded or cuboidal objects in the lower third, where a brief period of observation, not exceeding 12 hours, is recommended. Prolonged hold-up in this region is exceptional.

Stomach and Duodenum.-Conservatism is strongly recommended in most cases. The addition of large quantities of bread, porridge, and other additives-for example, cotton wool - to the diet will in no way protect the lining of the stomach and intestine from trauma by the foreign body. Active catharsis should certainly be avoided, as it would produce excessive peristalsis. In order to minimize radiation exposure all stools should be closely examined for the presence of foreign objects. Indications for operative intervention are (a) danger of perforation, especially by long slender objects in children less than 2 years old; and $(b)$ failure of progression for a minimum of 10-12 days.

Intestine.-A conservative approach is strongly recommended in all cases except where a complication has developed or in cases of very prolonged hold-up (minimum of two to three weeks).

The incidence of laparotomy and enterotomy for removal of ingested foreign bodies in the larger series reported in the medical literature is shown in Table IV.

TABLE IV-Incidence of Laparotomy for Ingested Foreign Body

\begin{tabular}{|c|c|c|c|}
\hline \multirow{2}{*}{ Series } & \multirow{2}{*}{$\begin{array}{l}\text { Total No. } \\
\text { of Cases }\end{array}$} & \multicolumn{2}{|c|}{ Laparotomy } \\
\hline & & No. & $\%$ \\
\hline 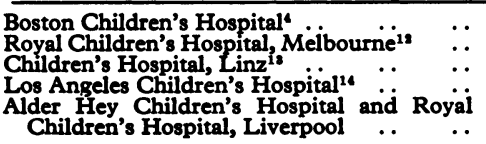 & $\begin{array}{l}766 \\
225 \\
128 \\
115 \\
660\end{array}$ & $\begin{array}{r}43 \\
9 \\
9 \\
26 \\
43\end{array}$ & $\begin{array}{r}5.6 \\
4.0 \\
7.0 \\
22.6 \\
6.5\end{array}$ \\
\hline
\end{tabular}

I would like to thank Mr. P. P. Rickham, director of paediatric surgical studies, University of Liverpool, for his permission to make this report and for his advice in its preparation.

\section{References}

1 Benson, C. D., and Lloyd, J. R., In Pediatric Surgery, 2nd ed., ed. W. T. Mustarde, M. M. Ravitch, W. H. Synder, K. J. Welch, and C. D. Benson, p. 825. Chicago, Year Book Medical Publications, 1969.

Mason Brown, J. J., Surgery of Childhood, p. 837. London, Arnold, 1962. White, M., and Dennison, W. M., Surgery in Infancy and Childhood, p. 262. Bdinburgh, Livingstone.

- Gross, R. E., Surgery of Infancy and Childhood, p. 250. Philadelphia, Saunders, 1953.

S Chrispin, A. R., Friedland, G. W., and Waterston, D. S., Thorax, 1966, $21,104$.

- Henderson, F. F., and Gaston, E. A., Archives of Surgery, 36, 66.

Tillespie, J. B., American Fournal of Diseases of Children, 1960, 80, 600.

Gillespie, J. B., American fournal of Diseases of Children, 1960

- Widome, A., Medical Annals of the District of Columbia, 27, 25.

10 Capen, N., and Wells, C., Archives of Disease in Childhood, 1938, 13,

1 Rosenquist, H., fournal of the Mount Sinai Hospital, 1948, 14, 929. $109,293$.

12 Jones, P. G., Medical fournal of Australia, 1963, 50, 236.

12 Geley, Von L., Deutsche medizinische Wochenschrift, 1969, 119, 25.

is Stevenson, E. O. S., and Hastings, N., American Surgeon, 1968, 34, 151. 